\title{
Metodologia de ensaios de emissões e eficiência energética em veículos híbridos elétricos leves. Um estudo da norma brasileira ABNT NBR16567, aplicada ao laboratório de emissões veiculares.
}

\author{
Leandro Cardoso ${ }^{1}$, Marcelo Massarani² \\ Escola Politécnica da USP (EPUSP) ${ }^{1}$ \\ E-mails: leandrocardoso.lc@hotmail.com; massara@usp.br
}

\section{RESUMO}

O setor de transportes é um dos mais afetados, com a implementação de novas políticas públicas e o estreitamento das legislações. Para atender as novas exigências, os fabricantes de veículos investiram pesado em P\&D de novas tecnologias de propulsão. Surgem então, os veículos híbridos, que agregam um motor à combustão com um ou mais motores elétricos, mostrando serem energeticamente mais eficientes e sustentáveis. Esta literatura, com base na ABNT NBR16567, apresenta a metodologia para realização dos ensaios de emissões e eficiência energética nesses veículos híbridos, abordando detalhadamente, a aplicação do regulamento na perspectiva do laboratório de emissões veiculares. O intuito é compreender melhor a metodologia dos dois tipos de ensaios praticados para a determinação das emissões de gases poluentes e do consumo energético desses veículos híbridos, de modo que seja possível entender as competências das partes envolvidas (montadoras, entidades governamentais e laboratórios de emissões). $\mathrm{Na}$ fase final, são avaliados os aspectos positivos e negativos da norma brasileira e os problemas enfrentados para realizar outras medições. Ao término, são apresentadas formas de atender a ABNT NBR16567 e conciliar os demais ensaios necessários na homologação de um veículo híbrido.

\section{INTRODUÇÃO}

\subsection{Enquadramento dos veículos híbridos}

A adoção de VEH's é indiscutível quanto às suas vantagens, pois é energeticamente melhor, produz baixo ruído e dispõem de baixa emissão de poluentes (desde que a eletricidade seja produzida de forma sustentável).

No primeiro semestre de 2017, no Brasil, foram vendidos mais VE's e VEH's, do que todo o ano de 2016, totalizando cerca de 4800 veículos elétricos e híbridos. [1]

De acordo com a Anfavea, houve um aumento no licenciamento de VE's ou VEH's, quando comparado o primeiro semestre de 2017 com o mesmo período de 2018, ao 
todo foram licenciadas 1944 unidades no primeiro semestre de 2018 contra 1184 no primeiro semestre de 2017 , um crescimento percentual de $64,2 \%$. [2]

De acordo com um estudo a comparação de custos entre os veículos convencionais e hibridizados vai mudar de forma expressiva a partir de 2020, em virtude dos avanços tecnológicos na bateria de Lítio, o que leva à redução do preço, e consequentemente o custo na adoção de veículos híbridos e elétricos. A pesquisa projeta para 2040, o consumo de 1900KWh de eletricidade, na substituição de 13 milhões de barris de petróleo por dia. [3]

Na Figura 1, observa-se a representatividade dos veículos verdes de $35 \%$ das vendas de veículos leves, e uma projeção de 41 milhões de unidades em 2040.

Figura 1 - Projeção global de vendas de elétricos e híbridos.

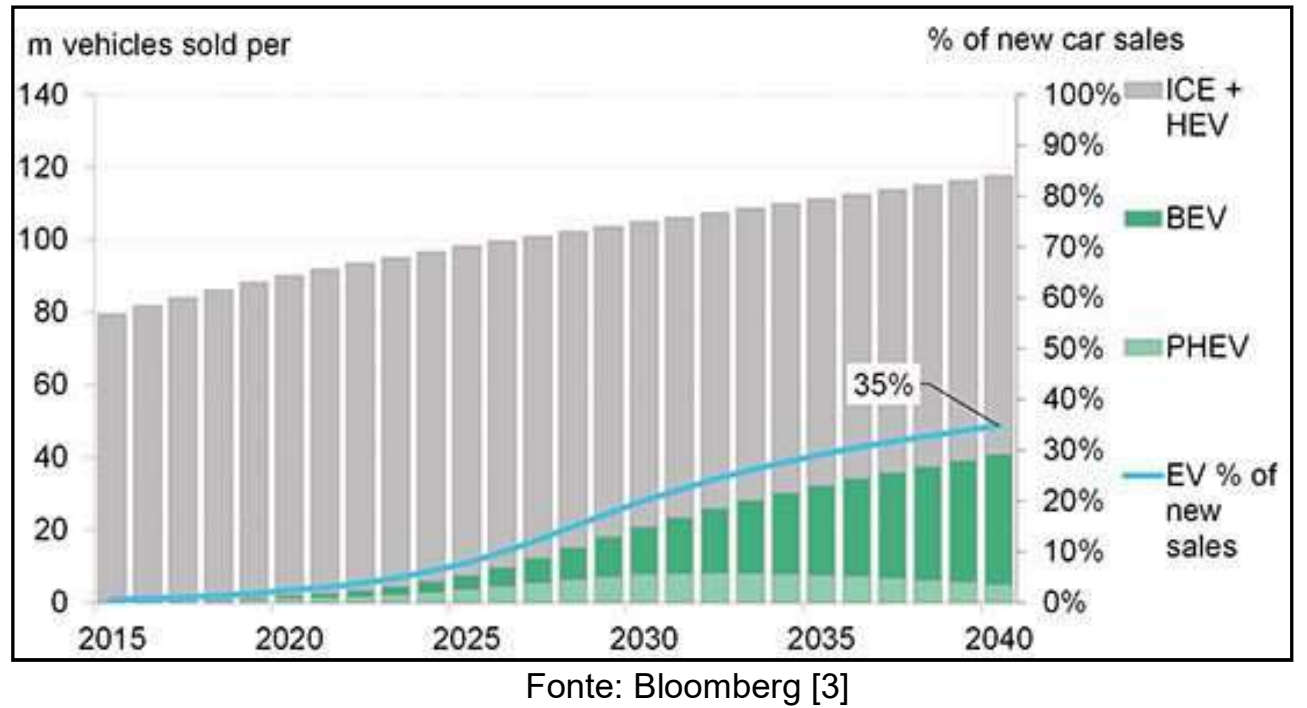

\subsection{Objetivo deste trabalho}

Especificamente, este trabalho objetiva explorar, a norma ABNT NBR16567, que é específica para a realização dos ensaios de emissões e de eficiência energética em VEH's.

A norma é elaborada pela comissão técnica de VE's e VEH's da AEA (Associação Brasileira de Engenharia Automotiva), baseando-se no regulamento americano SAE J1711.

A fase final visa contribuir, de forma objetiva e simplificada, as três partes de envolvimento direto com a norma: laboratório de emissões, fabricante e entidades de certificação. 


\section{TECNOLOGIA NOS VEÍCULOS HIBRIDOS}

Para a ABNT NBR16567, norma que é objeto de estudo deste trabalho, veículo elétrico híbrido é todo e qualquer veículo rodoviário propulsionado por meio de duas fontes de energia armazenáveis, sendo uma de um combustível consumível (etanol, gasolina, GNV), e como segunda fonte, um sistema recarregável de armazenamento de energia RESS (baterias de lítio, volantes eletromecânicos, capacitores). [4]

Os VEH's são classificados, em duas categorias, entre elas a arquitetura que dispõe de variados arranjos, e a outra é pelo nível de hibridização, que classifica de acordo com a maneira que o motor elétrico participa e contribui na propulsão do veículo e na recarga de energia.

Existem, basicamente, duas arquiteturas nos projetos híbridos, a arquitetura série e a paralela. Há também, uma terceira, que consiste no conjugado dessas duas arquiteturas. [6]

$\mathrm{Na}$ Figura 2, podemos ver as principais arquiteturas com tecnologia já desenvolvidas e presentes nos automóveis.

Figura 2 - Arquitetura dos veículos híbridos.

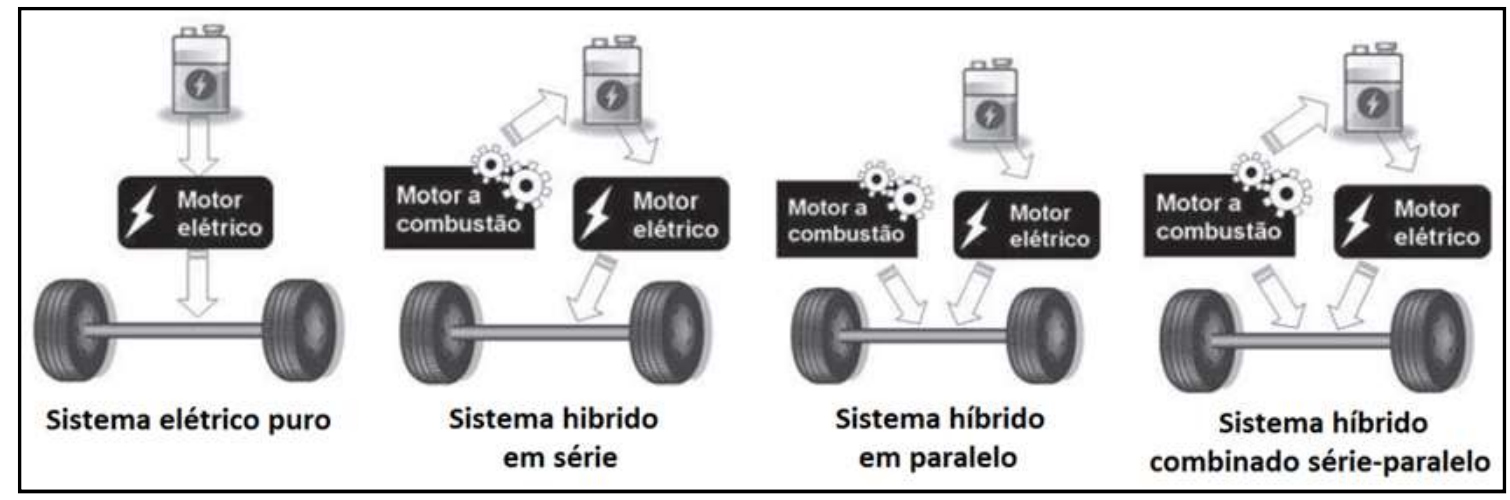

Fonte: Castro e Ferreira [6]

Os veículos híbridos, além de serem classificados pela arquitetura de seus sistemas, também são classificados pelo grau em que o motor elétrico move o veículo em relação à potência de tração total, denominando então "grau de hibridização".

$\mathrm{Na}$ equação (1) apresenta o fator de hibridização (HF), como conceito para determinar o nível de hibridização de um VEH. [7]

$$
\mathrm{HF}=\frac{\text { Pme }}{\text { Pme }+ \text { Pmci }}
$$

Onde, Pme é a potência do motor elétrico e Pmci é a potência do motor a combustão.

Na Tabela 1, é apresentado um resumo dos níveis de hibridização. 
Tabela 1 - Níveis de hibridização

\begin{tabular}{lcccc}
\hline Nível de Hibridização & $\begin{array}{c}\text { Micro } \\
\text { híbrido }\end{array}$ & $\begin{array}{c}\text { Híbrido } \\
\text { médio }\end{array}$ & $\begin{array}{c}\text { Híbrido } \\
\text { completo }\end{array}$ & $\begin{array}{c}\text { Híbrido } \\
\text { plug-in }\end{array}$ \\
\hline $\begin{array}{l}\text { Sistema de partida } \\
\text { Start-Stop }\end{array}$ & $\checkmark$ & $\checkmark$ & $\checkmark$ & $\checkmark$ \\
$\begin{array}{l}\text { Sistema de frenagem } \\
\text { regenerativa }\end{array}$ & $\times$ & $\checkmark$ & $\checkmark$ & $\checkmark$ \\
$\begin{array}{l}\text { Motor MCl assistido } \\
\text { pelo motor elétrico }\end{array}$ & $\times$ & $\checkmark$ & $\checkmark$ & $\checkmark$ \\
$\begin{array}{l}\text { Tracionamento pelo } \\
\text { motor elétrico e o MCl }\end{array}$ & $\times$ & $\times$ & $\checkmark$ & $\checkmark$ \\
$\begin{array}{l}\text { Permite carregamento } \\
\text { em tomada elétrica }\end{array}$ & $\times$ & $\times$ & $\times$ & $\checkmark$ \\
\hline
\end{tabular}

Fonte: Cardoso [8]

\section{METODOLOGIA}

\subsection{ABNT NBR16567}

A norma ABNT NBR16567 foi criada com base na norma americana SAE J1711, procedimento que é referência internacional em assuntos voltados à medição de emissões e consumo em veículos híbridos. Esta norma atua como complemento às normas ABNT NBR6601 e ABNT NBR7024, que estabelecem a metodologia de análise de emissões e de consumo para os veículos convencionais.

De acordo com o escopo da norma ABNT NBR16567 [4], seu objetivo é estabelecer uma metodologia uniforme aos ensaios realizados em dinamômetros de chassis, para medir e calcular os poluentes emitidos e o consumo de combustível e energia em VEH e VEHP.

Observa-se que a norma supracitada, remete de forma indispensável, as normas ABNT NBR 6601, ABNT NBR 7024, ABNT NBR 8689, ABNT NBR 10312 e SAE $\mathrm{J} 1634: 2012$, além de recorrer as "boas práticas da engenharia", para atender critérios que podem ser relativos a cada veículo ou aparelhagem envolvida.

O organograma na Figura 3 ilustra os métodos de ensaio estabelecido pela ABNT NBR16567. 
Figura 3 - Estrutura dos métodos de ensaio para VEH.

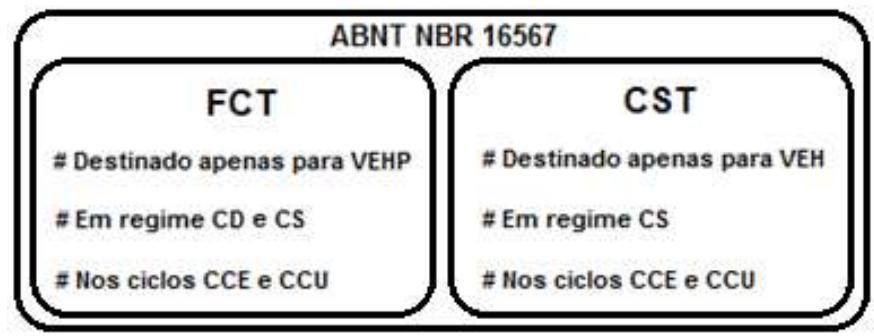

Fonte: Autores

\subsection{O laboratório de emissões e a aparelhagem complementar}

As instalações do laboratório de emissões devem ter capacidade e segurança adequadas, no que diz respeito à ventilação e troca de calor das baterias, proteção apropriada contra a exposição a alta tensão e nos demais cuidados com a segurança na execução dos ensaios e carregamento externo do RESS.

Figura 4 - Laboratório para ensaio.

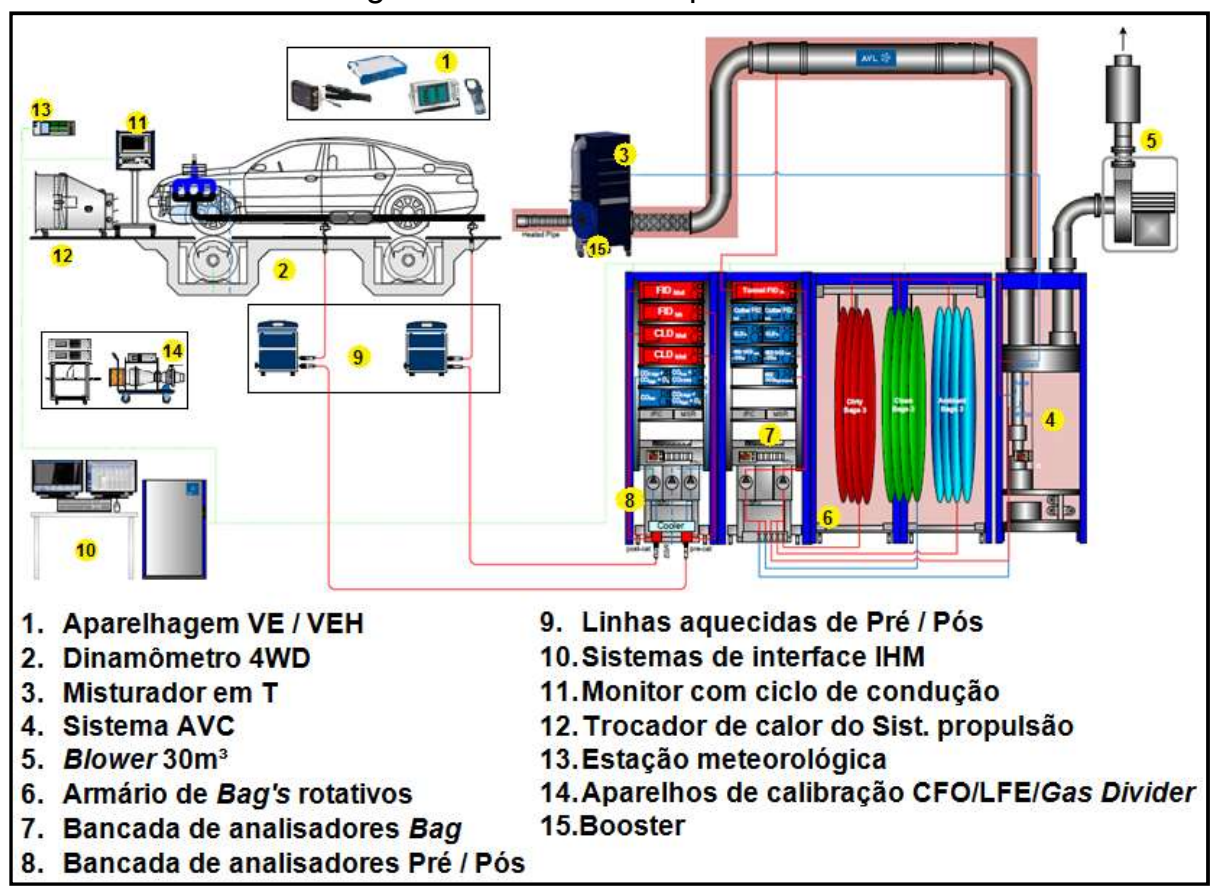

Fonte: Adaptado [9]

Algumas alterações na infraestrutura do laboratório são necessárias para a execução de ensaios em veículos híbridos, entre elas estão. O sistema de amostragem (AVC), que deve possuir automação adequada para rotatividade dos balões, pois devido a multiplicidade de ciclos de forma ininterrupta é importante que a análise, evacuação e purga dos balões ocorra em paralelo com o ensaio, de modo que o sistema de amostragem sempre possua um par de balões pronto para começar uma nova amostragem.

Para os ensaios em veículos híbridos elétricos, utiliza-se, também, um equipamento de reforço ao blower chamado de booster, que é acionado por meio de 
um sensor ultrassensível ao fluxo de gás de escape. Quando o motor $\mathrm{MCl}$ é desligado, durante um ensaio FCT/CST, o booster liga e aumenta o fluxo de ar ambiente e, a partir do princípio dinâmico da diferença de pressão dos fluídos, interrompe a coleta do gás de escape do veículo, a fim de preservar a temperatura do catalisador na condição nominal de trabalho. Já, quando o motor $\mathrm{MCl}$ está em funcionamento, o booster se mantém em condição de espera. [8]

Na Figura 5, podemos ver o equipamento de reforço instalado em um laboratório de emissões.

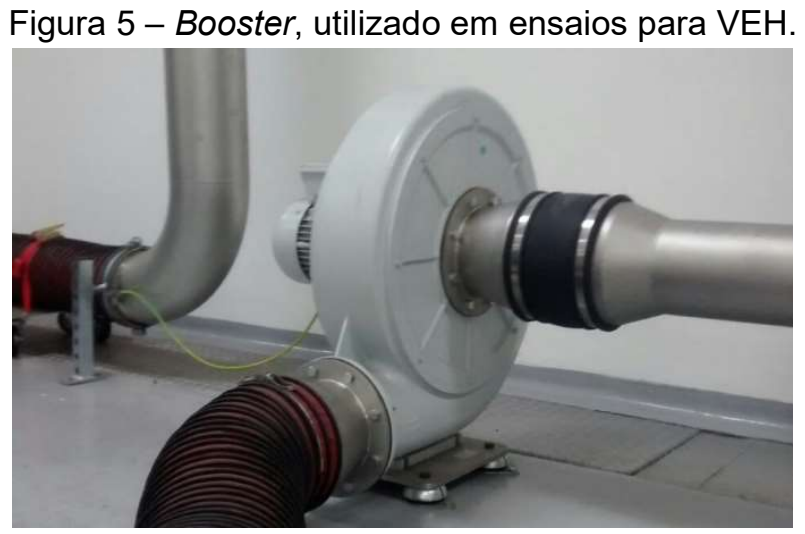

Fonte: Autores

Os dinamômetros usados em ensaios de VEH, a norma ABNT NBR 16567 atribui as especificações a ABNT NBR 6601, que determina que o dinamômetro deve ser munido de uma unidade de absorção de potência, podendo ser elétrica ou hidráulica e exige que possua um conjunto de volantes de inércia, ou sistema equivalente, a fim de simular a inércia do veículo. É recomendado também pela ABNT NBR 6601, o uso de dinamômetros de rolos duplos, com diâmetro nominal superior ou igual a $219 \mathrm{~mm}$ ou de rolos simples, com diâmetro nominal superior ou igual a $1200 \mathrm{~mm}$. Sobretudo a ABNT NBR 16567, sinaliza a preferência por dinamômetros do tipo elétrico de rolo simples de 48", e em casos de o VEH possuir tração nas quatro rodas aconselha-se a utilização de dinamômetro 4WD. [4] [5]

Figura 6 - VEH fixado em dinamômetro 4WD.

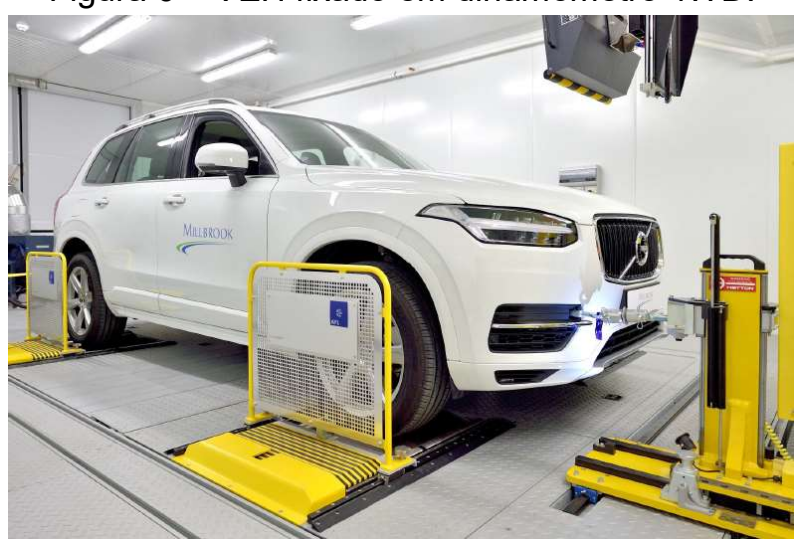

Fonte: Belleux e Salamon [10] 
Para os ensaios em veículos híbridos se faz necessário o uso de um analisador de potência para medir a redução de carga do RESS e determinar o SOC/NEC/EOT do ensaio. O medidor deve ter capacidade para mensurar tensão, corrente e energia em pelo menos dois canais. Contudo, em alguns casos pode ser necessária a utilização de mais canais. É importante que toda energia que entra pelo sistema regenerativo do RESS seja medida, bem como toda energia dissipada pelo RESS. Em resumo, medir tudo que entra e tudo que sai durante o ensaio, a fim de conhecer o SOC durante todo o processo. Podemos ver na Figura 7, um analisador de potência.

Figura 7 - Analisador de potência.

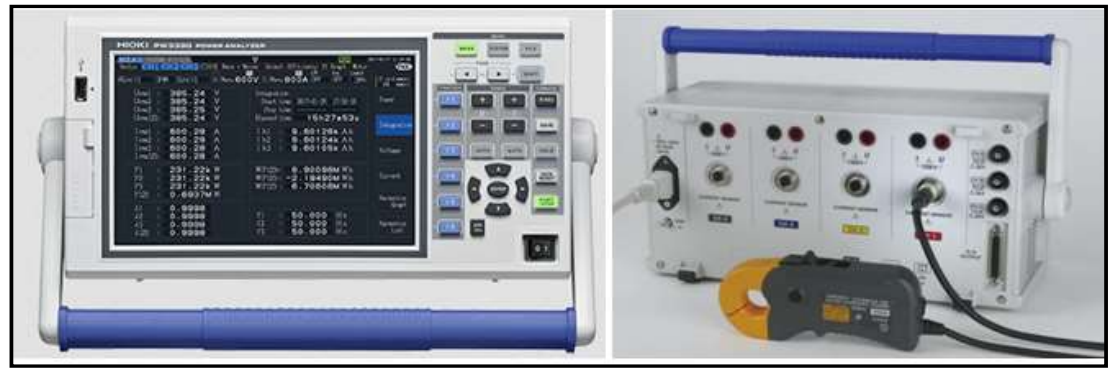

Fonte: Hioki [11]

O analisador de potência é conectado nos cabos de entrada e saída do RESS, por meio de alicates amperímetros, que têm como princípio de funcionamento a indução eletromagnética. Os devidos cuidados com a segurança devem ser observados durante qualquer procedimento que envolva alta tensão. Temos, na Figura 8, um esquema da instrumentação para ensaio.

Figura 8 - Esquema de ligação do analisador de potência.

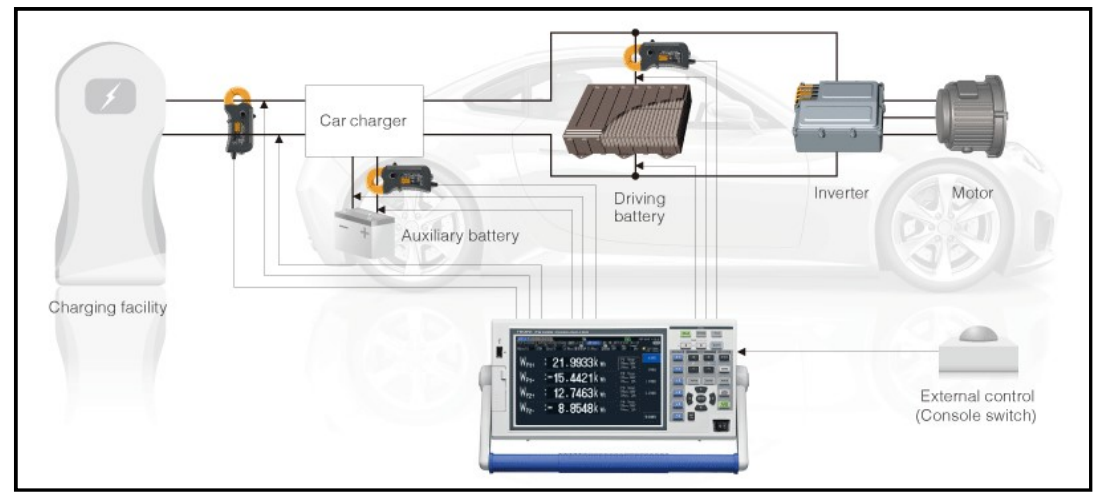

Fonte: Hioki [11]

Durante o ensaio é necessário conhecer a tensão (V) e o nível de carga do RESS, pois essas variáveis se fazem necessárias nos cálculos de NEC.

O acesso a essa informação se dá por meio da porta OBD do veículo, utilizando uma ferramenta de verificação compatível com o banco de ensaios do laboratório. $O$ sistema de diagnose de bordo (OBD) possui um protocolo de comunicação aberto e padronizado para todas as montadoras, a fim de facilitar o serviço de reparo eletrônico. No entanto, devido os veículos híbridos estarem se consolidando agora no mercado, os acessos a essas informações podem estar vedados ao usuário e à terceiros. No 
caso da impossibilidade de obter a informação do nível de SOC e de tensão do RESS, a montadora do veículo deverá fornecer essas informações ou o método adequado para extraí-las, e então proceder com a execução do ensaio.

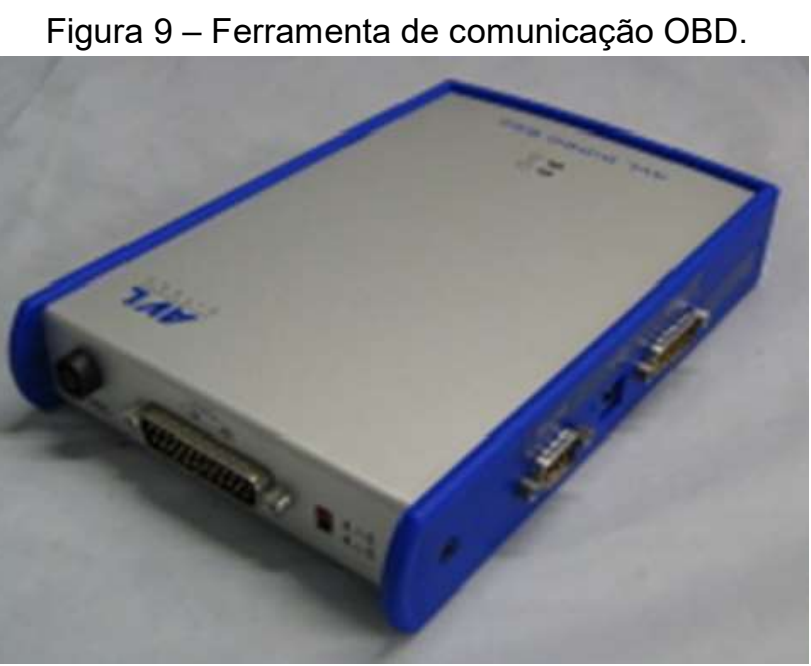

Fonte: AECS [12]

A norma ABNT NBR 16567 [4] recomenda que a distância percorrida no dinamômetro até o primeiro acionamento do motor $\mathrm{MCl}$ seja conhecida. Com o intuito de verificar a operação do motor, foi empregado o uso de um módulo de tempo de ignição, que contribui também, com o gerenciamento da amostra coletada, pois o dispositivo é usado em combinação com o sistema AVC, onde, através do cabo de vela ou de um dos fios que alimentam a bobina do injetor, os pulsos de ignição são convertidos e interpretado se o motor está em funcionamento.

Figura 10 - Módulo de tempo de ignição.

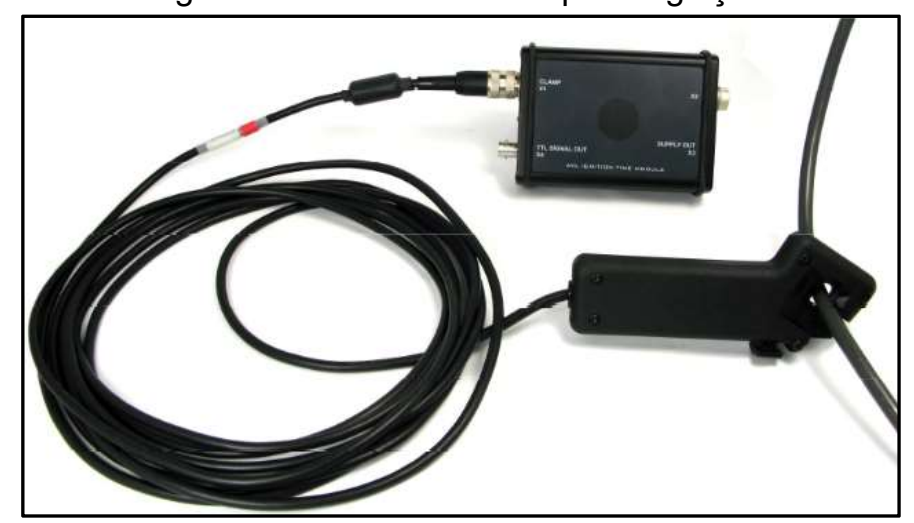

Fonte: AVL [13]

Segundo a norma ABNT NBR 16567 [4], se o veículo possuir um carregador desenvolvido pelo fabricante, este deve ser utilizado em todas as recargas necessárias ao ensaio, caso contrário, deve se utilizar um carregador que atenda as especificações do fabricante.

Na Figura 11, temos um carregador da Schneider Electric, que atende uma gama maior dos VEH's e VE's, pois possui múltiplos níveis de carga e tensão elétrica, além 
de possuir mais de um padrão de tomada para carregamento, e também pode ser visto um veículo da fabricante Tesla, sendo recarregado com o seu próprio carregador.

Figura 11 - (a) Estação de carregamento. (b) VE em carregamento com seu carregador.

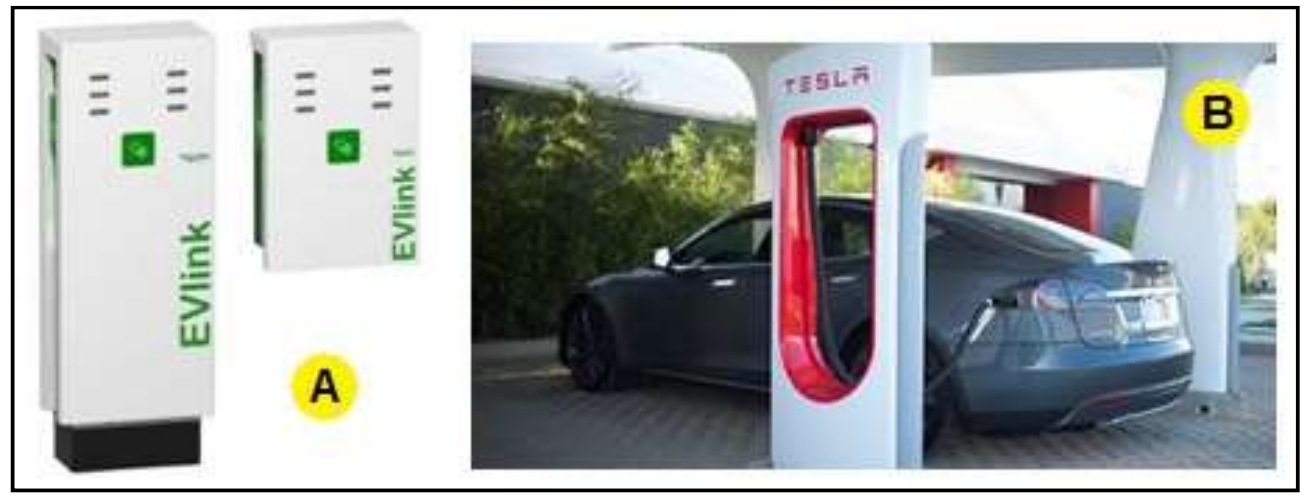

Fonte: Schneider [14]; Costa [15]

\section{ENSAIOS EM CARGA SUSTENTADA (CST)}

Este ensaio se aplica a todos os tipos de veículos híbridos (VEH, VEHP) no modo de operação contínua, tendo em vista simular a sua operação após o percurso na condição de redução de carga, ou seja, após o descarregamento parcial ou total do RESS, onde o veículo passa a operar por meio do consumo da energia do combustível, na condição de sustentar a carga do RESS.

Os ensaios CST têm por principal finalidade a medição de emissões dos gases de escapamento e do consumo de combustível, se reservando ao ensaio FCT a medição do balanço de carga do RESS. É importante ressaltar que ambos os tipos de teste são mensurados a depleção de carga do RESS bem como a emissão de poluentes.

Na Figura 12, temos o sequenciamento completo do ensaio CST em um veículo híbrido, dividido em três partes.

Figura 12 - Ensaio CST.

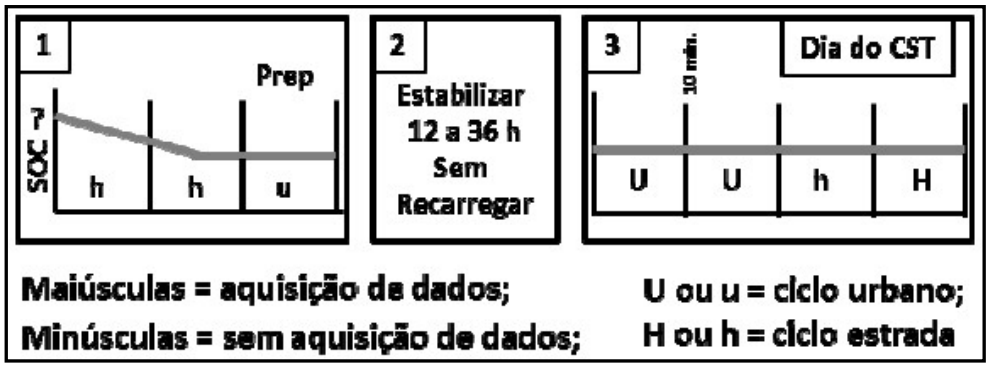

Fonte: ABNT NBR16567 [4] 


\section{ENSAIOS DE CARGA COMPLETA (FCT)}

Este ensaio se aplica apenas aos veículos híbridos plugin (VEHP), tendo em vista simular a sua operação no modo de redução de carga (CD) com o RESS totalmente carregado, ou seja, durante o descarregamento parcial do RESS, até onde o veículo passa a operar por meio do consumo da energia do combustível, na condição de sustentar a carga do RESS.

$\mathrm{Na}$ Figura 13, temos o sequenciamento completo do ensaio FCT em um veículo híbrido, dividido em seis etapas.

Figura 13 - Ensaio FCT.

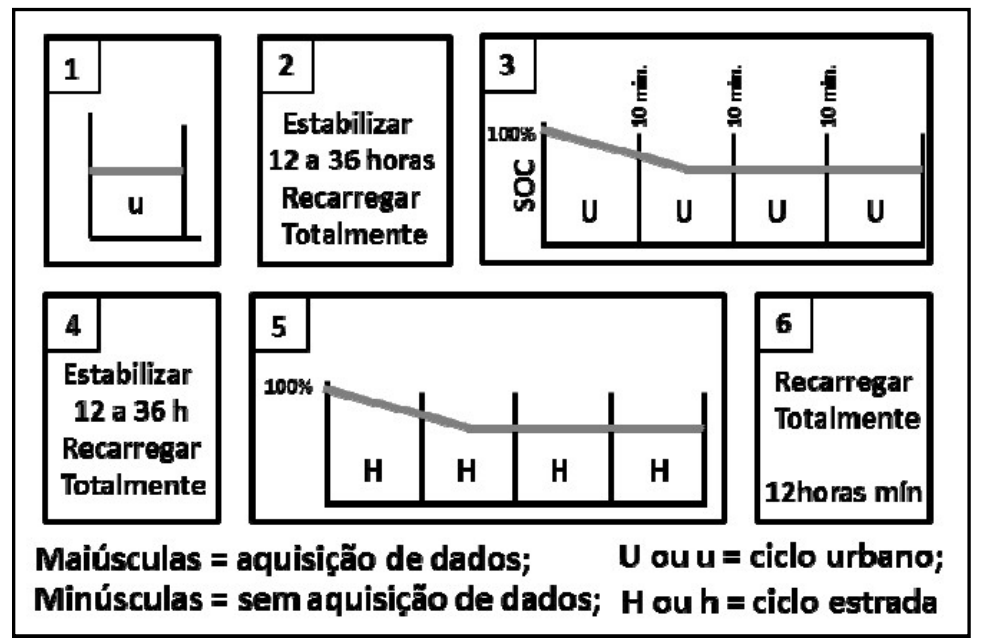

Fonte: ABNT NBR16567 [4]

$\mathrm{Na}$ Figura 14, temos o sequenciamento completo do ensaio FCT e o comportamento do nível de SOC em cada etapa do ensaio.

Figura 14 - Nível de SOC no ensaio FCT.

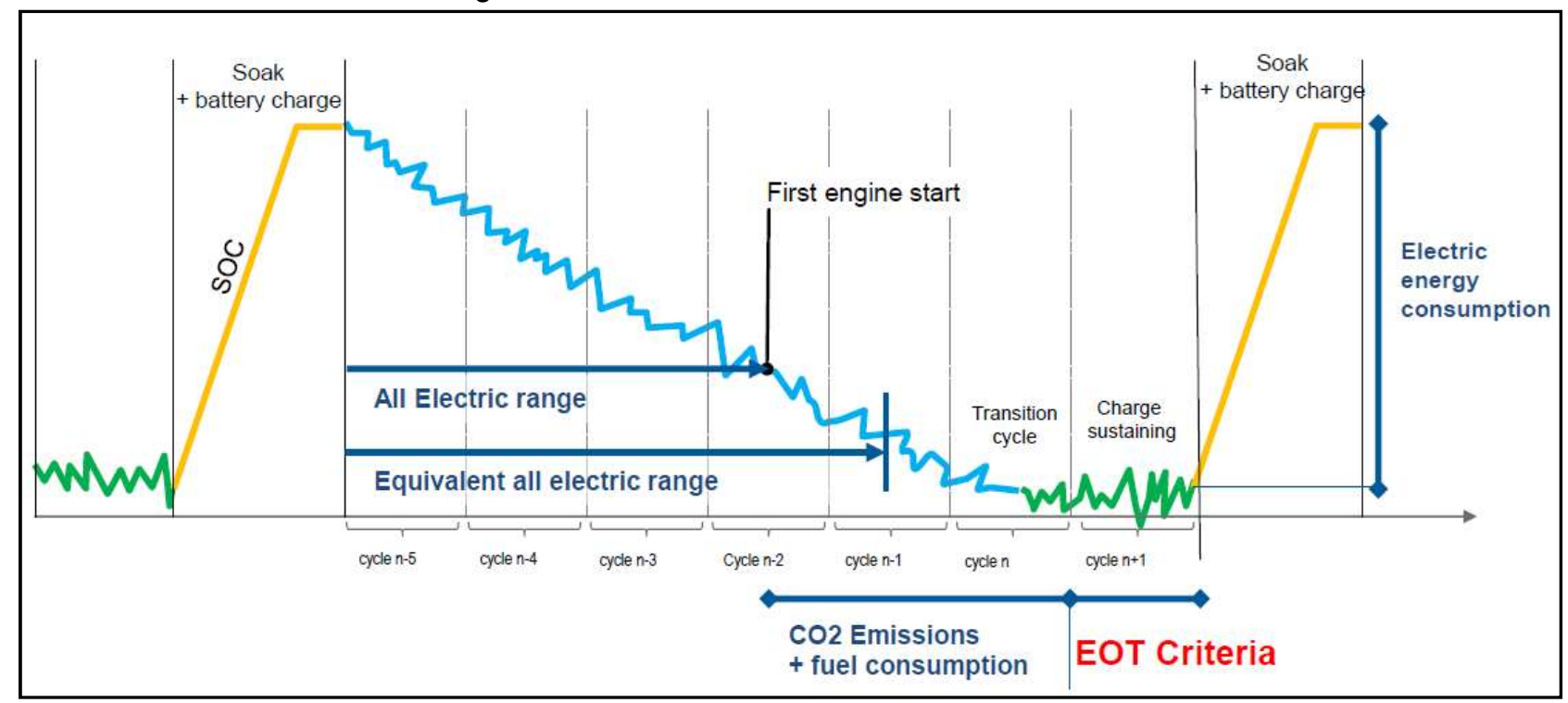

Fonte: Belleux [16] 


\section{PAUSAS ENTRE CICLOS, PARA ENSAIOS COM REDUÇÃO DE CARGA}

As pausas entre os ciclos devem ser de dez minutos para ciclo urbano e de quinze segundos para ciclo estrada, ao longo do maior número de ciclos possível. Durante as pausas não é permitido o carregamento do RESS por uma fonte externa de energia elétrica, pois o analisador de potência reservado para a medição do SOC, estará continuamente ligado durante todo o ensaio, incluindo as pausas entre ciclos. [4]

Se, por algum motivo, o laboratório não possuir automação e software apropriado que permita a rotatividade dos balões de amostragem, a fim de aplicar durante todo $o$ sequenciamento pausas de estabilização de dez minutos para CCU e de quinze segundos para CCE, é aceitável um intervalo de dez a trinta minutos para restabelecer o sistema de coleta e medição.

A Figura 15 representa as opções de pausas entre os ciclos de condução oferecidos pela norma ABNT NBR 16567. O fabricante do veículo deve escolher a melhor forma de realizar as pausas entre ciclos, pois um bom discernimento do comportamento da temperatura do RESS em periodos de estabilização pode oferecer ganhos ao nível de SOC.

Figura 15 - Opções de pausas entre ciclos.

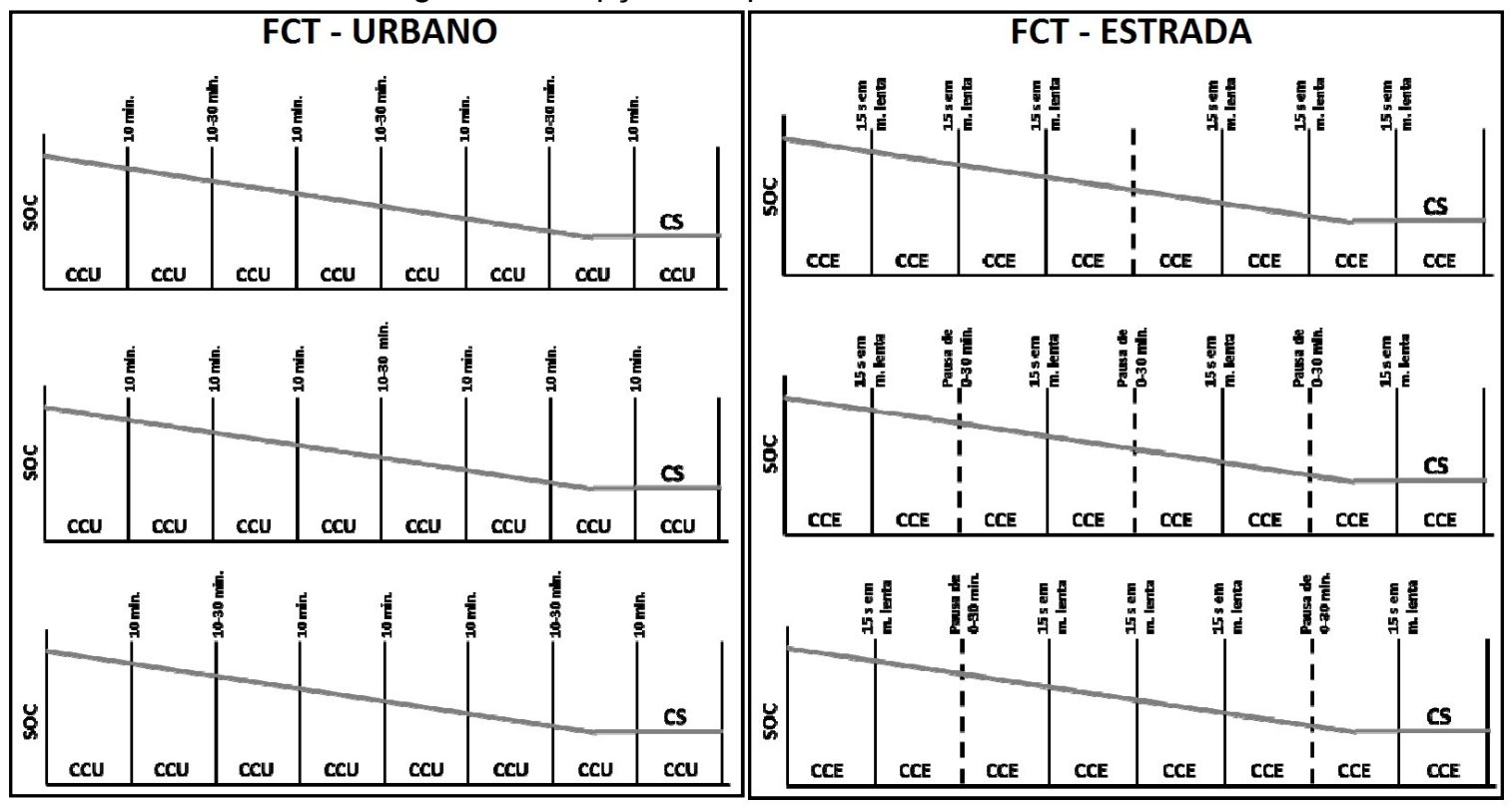

Fonte: ABNT NBR16567 [4]

\section{CRITÉRIO DE CONCLUSÃO DO ENSAIO (EOT)}

O critério de EOT é atendido quando ao final do primeiro ciclo em CS, ou mais ciclos, estiver compreendido dentro da tolerância da NEC. É comum que o primeiro ciclo em CS não atenda a tolerância da NEC e, por esse motivo, se a NEC acumulada ao longo dos ciclos for menor que $1 \%$, o critério de EOT pode ser considerado atingido. 
Contudo, alguns veículos podem ter dificuldades em atender a tolerância de NEC e, para esses casos, um critério alternativo foi elaborado. A filosofia é exatamente a mesma, apenas utiliza a capacidade total como critério de EOT, ou seja, se ao fim do ciclo CS o $\triangle S O C$ for menor que $2 \%$ da capacidade total esgotada, o ensaio chega ao fim.

Na Figura 16 temos a ilustração de vários exemplos de como o critério de EOT pode ser atingido.

Figura 16 - Cenários de critério de EOT.

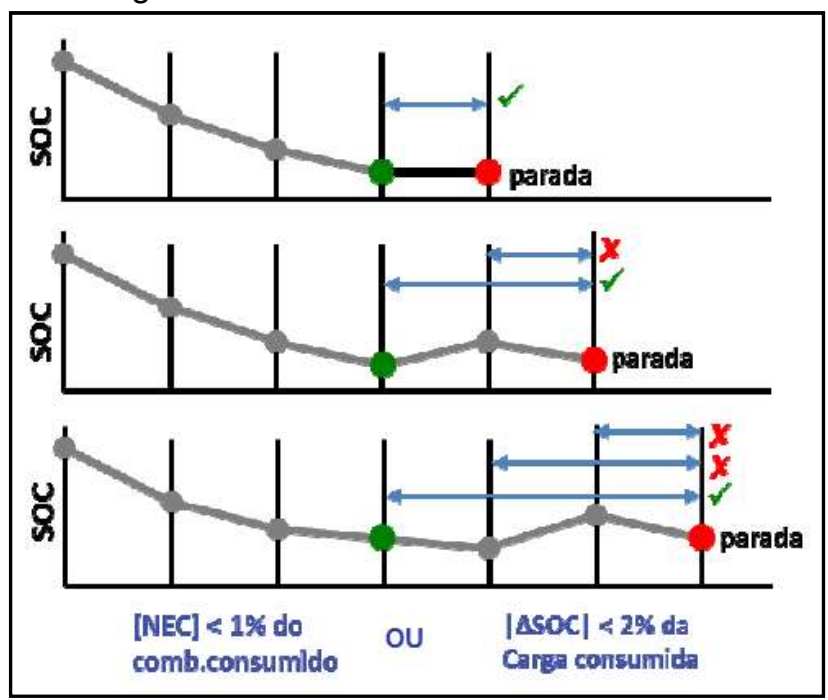

Fonte: ABNT NBR16567 [4]

\section{CONCLUSÃO}

- Os métodos de ensaio sugerem ser satisfatórios e condizentes com a realidade desses veículos no uso normal [8].

- Nenhum limite de emissões de poluentes foi estabelecido especificamente para veículos híbridos, os praticados para fins de homologação são o do PROCONVE PL6, nos quais atendem com tranquilidade, sobretudo é importante salientar que os VEH representam uma parcela pequena da frota nacional brasileira e o estabelecimento de um limite específico para esses veículos podem desestimular a hibridização da frota nacional.

- A coleta de aldeídos em veículos com tecnologia hibrida, não é tratada pelas normas ABNT NBR16567 e ABNT NBR12026, na Figura 17 é apresentado uma proposta para realizar a coleta e conciliar as duas normas. A proposta é realizar no dia do CST a coleta de aldeídos nos dois ciclos urbano, pois é garantido a participação do motor de combustão interna na propulsão do veículo nesses ciclos. 
Figura 17 - Proposta para coleta de aldeídos.

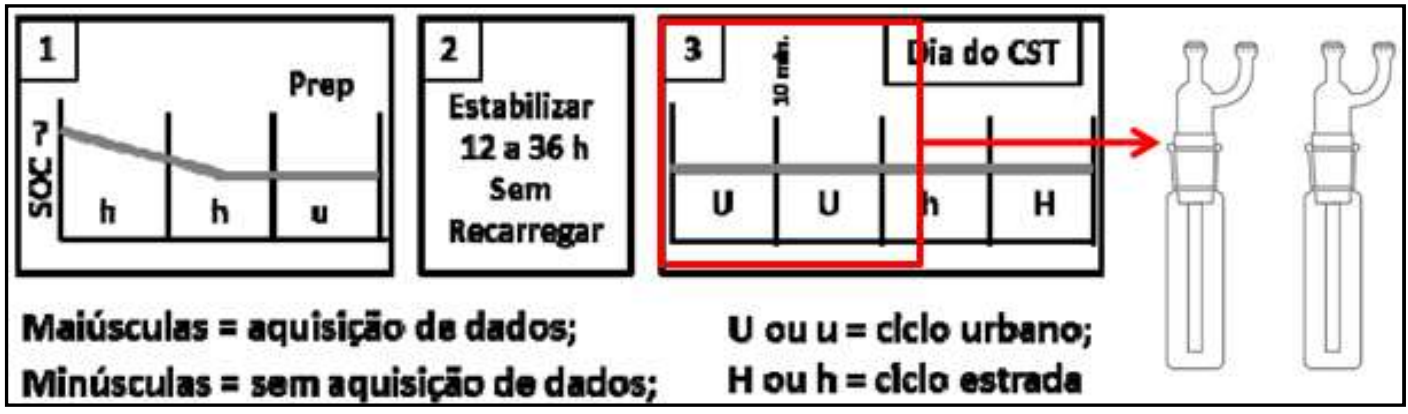

Fonte: Autores

- O PROCONVE L6 não trata acerca dos limites para a emissão evaporativa dos VEH's. No entanto, o limite estabelecido para os veículos convencionais de 1,5 gramas de hidrocarbonetos evaporado, parece ser adequado aos veículos híbridos, em virtude do RESS e todo o sistema de propulsão elétrico não ter influência nenhuma nos ensaios evaporativos a frio e a quente, pois os componentes do sistema de propulsão alternativo não contêm compostos voláteis com mudança de temperatura, sendo apenas o motor à combustão ou moto gerador do veículo diretamente envolvido em emissão de evaporativos. Contudo, as normas ABNT NBR 16567 e ABNT NBR 11481 não abordam a forma em que deve ser realizado o ensaio SHED, bem como em quais instantes deve ser executado o ensaio a frio e quente. Na Figura 18 é apresentado uma proposta para a realização do ensaio evaporativo (SHED) de acordo com os regulamentos vigentes, sobretudo deve ser discutido futuramente novos meios de realizar a medição de evaporativos, em razão da possível chegada do novo regimento automotivo "Rota 2030" que sinaliza para um prolongamento na duração desse ensaio. [8] [17]

Figura 18 - Proposta para execução do ensaio SHED.

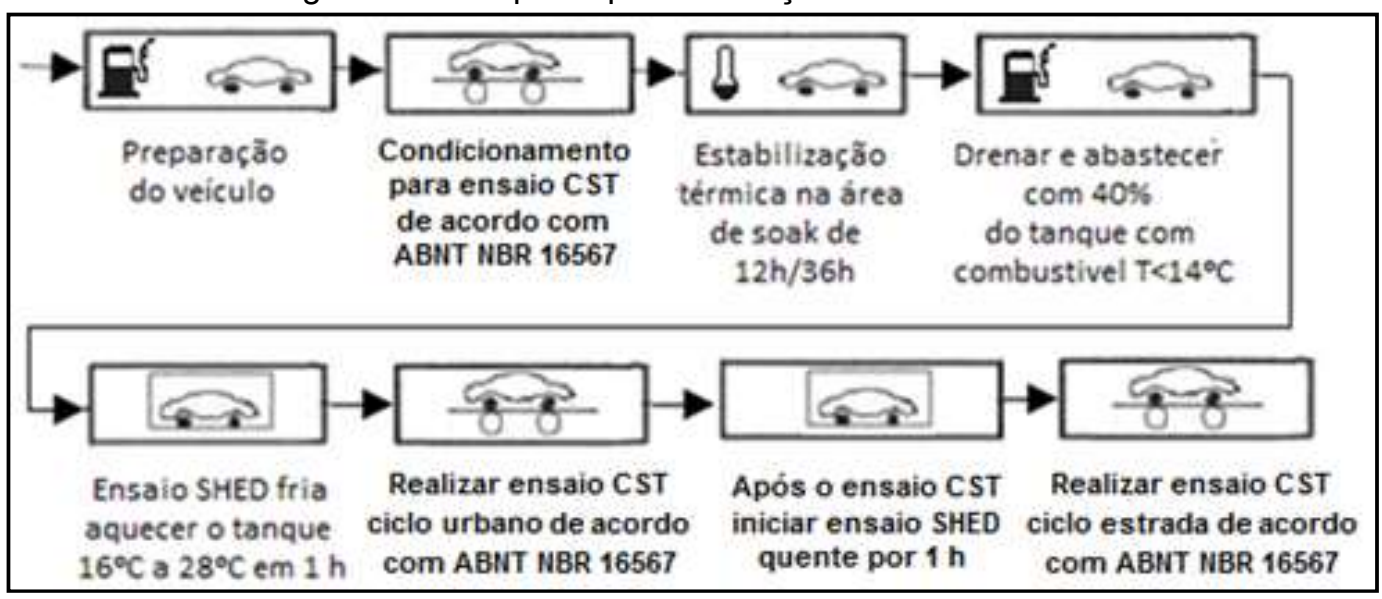

Fonte: Cardoso [8]

- Desinteresse dos laboratórios no atendimento do escopo da norma (investimento alto, baixa demanda e metodologia demorada). Em virtude de alguns VEHP possuirem um maior alcance no modo de redução de carga por conta da autonomia 
elevada do RESS, acabam prolongando os ensaios, pois é necessário a execução de um número maior de ciclos em regime de redução de carga do RESS e, consequentemente, elevar os gastos com horas de dinamômetro.

- Para alguns laboratórios pode ser pouco interessante a realização de investimentos em aparelhagem de medição de VEH, pois já possuem uma agenda de ensaios apertada e, abrir mão de vários clientes/projetos para atender apenas um, torna inviável a realização desses ensaios. Ainda sobre a aparelhagem o investimento é alto, e os equipamentos antigos não permite o retrofit para o atendimento ao escopo da norma. A Tabela 2, apresenta a distribuição, ao longo dos dias, de uma sequência completa dos ensaios de um VEHP nos dois ciclos, em carga sustentada (CST) e em regime de descarga do RESS (FCT). Observase a necessidade de, pelo menos seis dias de ensaios para a realização de uma sequência completa (CST + FCT), sem contar com eventuais imprevistos que podem ocorrer e inviabilizar a realização do ensaio.

Tabela 2 - Distribuição dos ensaios na semana.

\begin{tabular}{|c|c|c|}
\hline DIA 1 & DIA 2 & DIA 3 \\
\hline $\begin{array}{l}\text { Recebimento do } \\
\text { veículo }\end{array}$ & $\begin{array}{c}\text { Pré } \\
\text { Condicionamento } \\
\text { para ensaio CST }\end{array}$ & $\begin{array}{c}\text { Ensaio CST (urbano } \\
\text { e estrada) }\end{array}$ \\
\hline Instrumentação & $\begin{array}{c}\text { Soak térmico }(12 \mathrm{~h} \mathrm{a} \\
36 \mathrm{~h})\end{array}$ & $\begin{array}{c}\text { Pré } \\
\text { Condicionamento } \\
\text { FCT }\end{array}$ \\
\hline $\begin{array}{c}\text { Drenagem e } \\
\text { abastecimento }\end{array}$ & & $\begin{array}{c}\text { Soak térmico ( } 12 \mathrm{~h} \text { a } \\
36 \mathrm{~h}+\text { recarga do } \\
\text { RESS) }\end{array}$ \\
\hline DIA 4 & DIA 5 & DIA 6 \\
\hline $\begin{array}{l}\text { Ensaio FCT } \\
\text { (urbano) }\end{array}$ & $\begin{array}{l}\text { Ensaio FCT } \\
\text { (estrada) }\end{array}$ & $\begin{array}{l}\text { Remoção da } \\
\text { instrumentação }\end{array}$ \\
\hline $\begin{array}{c}\text { Soak térmico ( } 12 \mathrm{~h} \text { a } \\
36 \mathrm{~h}+\text { recarga do } \\
\text { RESS) }\end{array}$ & $\begin{array}{c}\text { Recarga total do } \\
\text { RESS }\end{array}$ & $\begin{array}{l}\text { Devolução do } \\
\text { veículo }\end{array}$ \\
\hline
\end{tabular}

Fonte: Cardoso [8]

- Para laboratórios que possuem um único banco de ensaios e suas atividades se concentram no horário administrativo, sem dúvida é inviável se adequar para atender o escopo da norma ABNT NBR 16567, pois devem investir em treinamento e capacitação profissional como por exemplo a norma de segurança no trabalho NR-10 que estabelece diretrizes com relação a segurança na realização de serviços com eletricidade.

- A falta da adoção de um padrão em relação aos conectores e plugs para o carregamento se evidencia nos ensaios que exigem o carregamento do RESS. Os laboratórios em que forem realizar os ensaios em veículos híbridos, devem passar por adaptações e adequações de aterramento, para atender os múltiplos níveis de 
carga e tensão elétrica e possuir, pelo menos, dois padrões de tomada / carregadores para carregamento (SAE e IEC).

Figura 19 - Padrões de carregamento disponíveis atualmente.

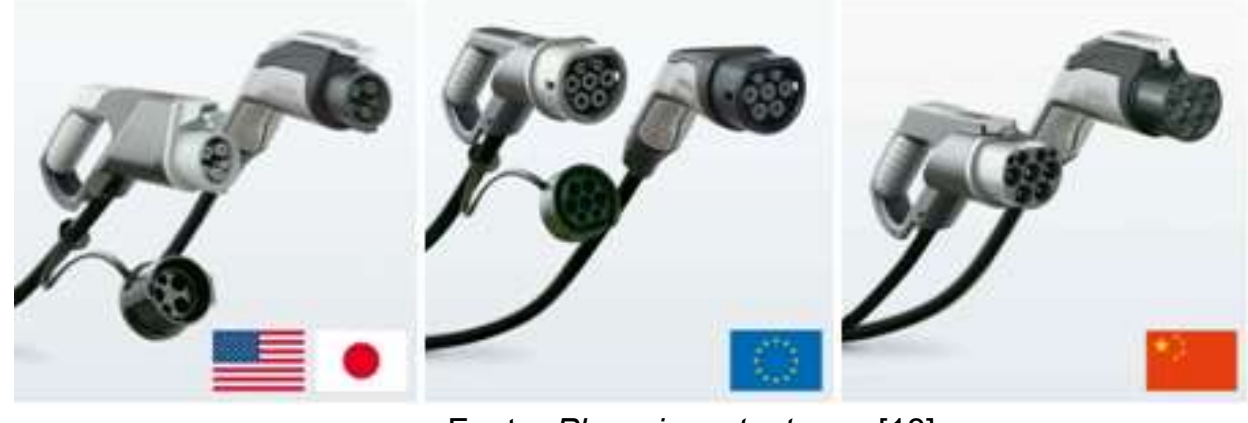

Fonte: Phoenixcontact.com [18]

- Mais debates para entender o papel do VEH no novo regimento automotivo "Rota 2030", PL7, PBEV e outros programas do governo, sempre buscando promover a proliferação desses veículos híbridos e elétricos na frota nacional, visto que a eletrificação do mercado automotivo é globalizada.

\section{ABREVIATURAS E DEFINIÇÕES}

$\begin{array}{ll}\text { ABNT } & \text { Associação Brasileira de Normas Técnicas } \\ \text { AEA } & \text { Associação Brasileira de Engenharia Automotiva } \\ \text { ANFAVEA } & \text { Associação Nacional dos Fabricantes de Veículos Automotores } \\ \text { AVC } & \text { Amostrador de Volume Constante } \\ \text { CCE } & \text { Ciclo de Condução Estrada } \\ \text { CCU } & \text { Ciclo de Condução Urbano } \\ \text { CD } & \text { Redução de Carga } \\ \text { CS } & \text { Carga Sustentada } \\ \text { CST } & \text { Ensaios em Carga Sustentada } \\ \text { EOT } & \text { Instante Final do Ensaio } \\ \text { FCT } & \text { Ensaio de Carga Completa } \\ \text { FTP } & \text { Federal Test Procedure } \\ \text { GNV } & \text { Gás Natural Veicular } \\ \text { HF } & \text { Fator de Hibridização } \\ \text { HWFET } & \text { Ciclo de Condução Estrada } \\ \text { MCI } & \text { Motor de Combustão Interna } \\ \text { NBR } & \text { Norma Brasileira } \\ \text { NEC } & \text { Variação do Estado de Carga do RESS } \\ \text { OBD } & \text { On Board Diagnose } \\ \text { PBEV } & \text { Programa Brasileiro de Etiquetagem Veicular } \\ \text { PL6 } & \text { PROCONVE leves 6 } \\ \text { PL7 } & \text { PROCONVE leves 7 } \\ \text { PROCONVE } & \text { Programa de Controle da Poluição do Ar por Veículos } \\ \text { RESS } & \text { Sistema de Armazenamento de Energia Recarregável }\end{array}$




$\begin{array}{ll}\text { SAE } & \text { Society of Automotive Engineers EUA } \\ \text { SHED } & \text { Sealed Housing for Evaporative Determination } \\ \text { SOC } & \text { Nível de Carga do RESS } \\ \text { VE } & \text { Veículo elétrico } \\ \text { VEH } & \text { Veículo Elétrico Híbrido } \\ \text { VEHP } & \text { Veículo Elétrico Híbrido Plug-in }\end{array}$

\section{REFERÊNCIAS}

[1] MENEZES, S. Recife. Carros híbridos são o futuro possível. Disponível em: $<$ http://www.abve.org.br/noticias/carros-hibridos-sao-o-futuro-possivel> Acesso em: 11 Ago. 2017.

[2] ANFAVEA. Carta Digital Disponível em: <http://www.anfavea.com.br/carta digital/06-julho/index.html\#p=6 > Acesso em: 14 Jul 2018.

[3] BLOOMBERG. São Paulo. Veículos elétricos representarão 35\%... Disponível em: $\quad<$ https://www.bloomberg.com.br/blog/veiculos-eletricos-representarao-35-dasvendas-globais-carros-novos-ate-2040/> Acesso em: 12 Ago. 2017

[4] ASSOCIAÇÃO BRASILEIRA DE NORMAS TÉCNICAS. NBR 16567: Veículos rodoviários híbridos elétrico leves - Medição de emissão de escapamento e consumo de combustível e energia - Método de ensaio. Rio de Janeiro, 2016. 55 p.

[5] ASSOCIAÇÃO BRASILEIRA DE NORMAS TÉCNICAS. NBR 6601: Veículos rodoviários automotores leves - Determinação de hidrocarbonetos, monóxido de carbono, óxidos de nitrogênio, dióxido de carbono e material particulado no gás de escapamento. Rio de Janeiro, 2012. 49 p.

[6] CASTRO, B. H. R; FERREIRA, T. T. BNDES Veículos elétricos: Aspectos básicos, perspectivas e oportunidades. São Paulo: [s.n], 2011. 267 - 310 p. Disponível em:

$<$ https://web.bndes.gov.br/bib/jspui/bitstream/1408/1764/1/BS\%2032\%20Veículos\%2 0elétricos\%20aspectos\%20básicos\%2c\%20perspectivas P.pdf>. Acesso em: 20 Ago. 2017.

[7] MAGALHÃES, B. F. O. Hibridação de veículo automóvel. 2014. 158 p. Dissertação Mestrado - Faculdade de engenharia de universidade do Porto, Portugal, 2014. Digital.

[8] CARDOSO, L. Metodologia de ensaios de emissões e eficiência energética em veículos híbridos elétricos leves... 2017. 114 p. Dissertação lato sensu - Escola Politécnica da USP, São Paulo, 2017. Digital

[9] AVL. Manual de operação Dinamômetro de chassis: Com interface homem máquina MMI.Neuss, 2013. 111 p. 1. Apresenta os modos de operação do dinamômetro de chassis. 
[10] BELLEUX, R; SALAMON, A. AVL Abgasrollnprüfstände: Implikation gesetzlicher AnforderungenIn: AVL, 2017 [S.I.]. Emission test systems. [S.I.]: 15 Maio. 2017. p. 1-58. Digital.

[11] HIOKI. Japão. Power analyzer PW3390. Disponível em: $<$ https://www.hioki.com/en/products/detail/?product key=6413>Acesso em: 10 Set. 2017

[12] AECS. [s.l.] AVL DIOBD 880 Scan Tool Disponível em: $<$ http://www.aecs.net/products/avl/dix\%20emission\%20software/dixscan.htm> Acesso em:15 Set. 2017

[13] AVL. Graz. Ignition time module 380 . Disponível em: <https://www.avl.com/documents/10138/885965/Productdescription 380 E.pdf> Acesso em:15 set. 2017.

[14] SCHNEIDER. [s.l]. EVlink Parking. Disponível em: <http://www.schneiderelectric.com.ng/en/product-range/60850-evlink-parking/> Acesso em: 09 set. 2017.

[15] COSTA, E. [s.I.] Rede mundial de carregamento da Tesla é a que mais cresce. Disponível em: <http://www.verdesobrerodas.com.br/2015/09/rede-mundial-decarregamento-da-tesla-e.html> Acesso em: 09 set. 2017.

[16] BELLEUX, R. Hybrid emission application: Chassis dyno test cell reference solution In: AVL, 2015 [S.I.]. Emission test systems. [S.I.]: 18 Set. 2015. p. 1-58. Digital.

[17] ASSOCIAÇÃO BRASILEIRA DE NORMAS TÉCNICAS. NBR 11481: Veículos rodoviários automotores leves - Medição da emissão evaporativa. Rio de Janeiro, 2010. $10 \mathrm{p}$.

[18] PHOENIX CONTACT. Portugal. Conector de carga para veículos CA com logótipo personalizável.

Disponível em:

<https://www.phoenixcontact.com/online/portal/pt/pxc/content pages/lut/p/z1/> Acesso em: 09 Nov. 2017. 